\title{
Nanogram Per Milliliter Per Milligram Per Kilogram Per Day
}

National Cancer Institute

\section{Source}

National Cancer Institute. Nanogram Per Milliliter Per Milligram Per Kilogram Per Day. NCI Thesaurus. Code C105478.

A dose calculation unit expressed in nanograms per milliliter, divided by milligram per kilogram per day. 